\title{
The daily fluorine and arsenic intake for residents with different dietaries and fluorosis risk in coal-burning fluorosis area, Yunnan, Southwest China
}

\author{
Ling Li • Kun-li Luo • Yue-gang Tang • Yong-lin Liu
}

Received: 16 June 2014 / Accepted: 18 August 2014 / Published online: 29 August 2014

(C) Springer-Verlag Berlin Heidelberg 2014

\begin{abstract}
The daily fluorine (F)/arsenic (As) intake (DFI/ DAsI) for residents at different ages with different dietaries and dietary changes was investigated to analyze the fluorosis risk in coal-burning fluorosis area in Yunnan, Southwest China. The DFI for residents with a dietary of roasted corn and roasted chili was 5.06, 9.60, and $14.38 \mathrm{mg}$ for age groups $3-7,8-15$, and over 15 years, respectively. Over $90 \%$ of DFI was from roasted foodstuffs. The DFI for residents of the same age group living on rice and roasted chili was 1.94, 3.50, and $4.95 \mathrm{mg}$, respectively, which were less than that for the former dietary type, and $65 \%$ of DFI was from roasted chili. The main sources for their DFI are roasted foodstuffs. Both were higher than the dietaries with non-roasted foodstuffs and the recommended daily allowances (RDAs) for USA and China at different levels. The DAsI for all residents ranged from 25 to $135 \mu \mathrm{g}$, and at this level of DAsI, it would not influence
\end{abstract}

Responsible editor: Philippe Garrigues

Electronic supplementary material The online version of this article (doi:10.1007/s11356-014-3485-4) contains supplementary material, which is available to authorized users.

L. Li $\cdot$ K.-1. Luo $(\varangle) \cdot$ Y.-1. Liu

Institute of Geographic Sciences and Natural Resources Research,

Chinese Academy of Sciences, 11A Datun Road, Beijing 100101,

China

e-mail: luokl@igsnrr.ac.cn

K.-. Luo

e-mail:kunliluo@sohu.com

L. Li

e-mail: lzhliling@126.com

L. Li · Y.-g. Tang

China University of Mining and Technology (Beijing), 11D Xueyuan

Road, Beijing 100083, China human health. However, As pollution of roasted foodstuffs might have an important influence for the fluorosis. Residents are changing their staple food from roasted corn to rice, and especially, younger people are more focused on quality life. However, even if residents change their staple food, the habit of eating chili will not change, which also may cause them getting fluorosis. Developing economy, changing dietary types, and changing the habit of drying and keeping chili will help to reduce the fluorosis risk in coal-burning fluorosis area of Southwest China.

Keywords Daily fluorine intake · Daily arsenic intake · Roasted foodstuffs · Dietary types · Dietary development . Fluorosis risk

$\begin{array}{ll}\text { Abbreviations } \\ \text { F } & \text { Fluorine } \\ \text { As } & \text { Arsenic } \\ \text { DC } & \text { Dental caries } \\ \text { DF } & \text { Dental fluorosis } \\ \text { SF } & \text { Skeletal fluorosis } \\ \text { AI } & \text { Adequate intake } \\ \text { RDAs } & \text { Recommended daily allowances } \\ \text { DFI } & \text { Daily fluorine intake } \\ \text { DAsI } & \text { Daily arsenic intake } \\ \text { IOD } & \text { Improved oven for defluorination } \\ \text { PLFs } & \text { Permitted levels of fluorine } \\ \text { PLAs } & \text { Permitted levels of arsenic }\end{array}$

Introduction

Fluorine $(\mathrm{F})$ is an essential trace element for humans, because it plays an important role in the mineralization of bones and 
formation of dental enamel (Bell and Ludwig 1970). The deficiency of $\mathrm{F}$ may result in dental caries (DC) for children. However, excessive intake of $F$ may have cumulative toxic symptoms such as dental fluorosis (DF) and skeletal fluorosis (SF) (Liteplo et al. 2002; Kaseva 2006) and other adverse health effects such as bone cancer, Down's syndrome, and renal failure (Harrison 2005).

Researchers have paid much attention to the dose-response relationships and tried to determine the safe doses (Cao et al. 1996; Jian and Chen 2006; Ponikvar et al. 2007; Xiang et al. 2009). The adequate intake (AI) for $F$ from all sources is set at $0.05 \mathrm{mg} / \mathrm{day} / \mathrm{kg}$ of body weight, which is recommended for all ages greater than 6 months; it is because it confers a high level of protection against DC and is associated with unknown and unwanted health effects (FNB 1997). In the USA, the recommended daily allowances (RDAs) are 1.5-2.5 $\mathrm{mg}$ /day for children aged 4-7 years and 1.5-4 mg/d for adults, respectively (BCLSNR 1980, 1989). The WHO guideline for daily intake is $2 \mathrm{mg} /$ day for children and $4 \mathrm{mg}$ /day for adults, respectively (WHO 1985, 2002). Accordingly, AI of 3.1$3.8 \mathrm{mg} /$ day of $\mathrm{F}$ for adults is set and accepted by the German and Austrian Nutrition Society and the Swiss Nutrition Association (Reference Values for Nutrition Intake 2002). In China, the RDAs are different for different types of fluorosis area: The RDA for children aged $8-15$ years is $2.0 \mathrm{mg} /$ day, and for adults over 15 years, it is $3.0 \mathrm{mg}$ /day in coal-burning fluorosis area, while the RDA for children aged $8-15$ years is $2.4 \mathrm{mg} / \mathrm{day}$, and for adults over 15 years, it is $3.5 \mathrm{mg}$ /day in drinking water fluorosis area (WS/T87-1996).

There are mainly three types of endemic fluorosis: high-F drinking water (Abida et al. 2007; Mandinic et al. 2010), highF brick tea (Cao et al. 1996, 2003), and coal-burning fluorosis (Ando et al. 2001; Finkelman et al. 1999; Dai et al. 2004, 2007, 2012). Zhaotong, in Yunnan, is a serious coal-burning endemic fluorosis area (Ye et al. 2004a, b; Luo et al. 2007, 2008, 2010, 2011; Li et al. 2012). There were 2,000,000 DF patients and 600,000 SF patients (Ye et al. 2004a), and the occurrence rate of DF patients still exceeded $50 \%$ (Ye et al. 2004a, b). Furthermore, most elder fluorosis patients are also suspected with As poisoning, which is characterized by pigment precipitation (Luo et al. 2008). The serious influence of $\mathrm{F}$ on human health might be related with the combined effects of As-polluted roasted foodstuffs (An et al. 1992; Li et al. 1996; Luo et al. 2008; Dai et al. 2012).

In our previous study, we find that severe fluorosis areas and non-fluorosis areas exist in the same region and there are non-infected people in severe fluorosis areas and infected people in non-fluorosis areas in Southwest China as well (Luo et al. 2011). The prevalence rate of DF for children with different dietary types differs evidently: The prevalence rate of DF for children living on roasted corn before the age of 6 years is $100 \%$ with nearly $95 \%$ having mild to severe DF, while the prevalence rate of DF for children living on non-roasted corn or rice is very low and all with very mild DF (Luo et al. 2011). However, several problems still need further studies. What are the differences in daily F/As intake (DFI/DAsI) for residents at different age groups and having different dietary types? What percentages of DFI/DAsI from different sources, including kinds of foodstuffs, drinking water, and air, are in total DFI/DAsI having different dietary types? Furthermore, what are the local residents' present dietary habits and how does it change in the future? From the current level of economic situation and the dietary habits of local residents, will the fluorosis phenomenon disappear naturally in the future?

To prevent fluorosis from happening, the $\mathrm{F}$ and As concentrations in the commonly consumed foodstuffs and drinking water and their consumption amount of residents at different ages were investigated to estimate the daily $\mathrm{F}$ and As intake, and the development process of their dietary types was carried out in "coal-burning" fluorosis in Zhaotong, Yunnan, Southwest China.

\section{Material and methods}

\section{Study area}

Zhaotong is at the junction of Sichuan, Yunnan, and Guizhou, and has a subtropical and warm plateau monsoon climate. Its topography varies and is complicated with plateaus, hills, basins, and valleys. The climate varies with the altitude: It is cool and rainy with an average annual temperature of $11-$ $18{ }^{\circ} \mathrm{C}$ and an average annual precipitation of $900-1,200 \mathrm{~mm}$ at high altitudes, and it is comparatively dry and warm with an average annual temperature of $15-20{ }^{\circ} \mathrm{C}$ and an average annual precipitation of $660-1,000 \mathrm{~mm}$ at low altitudes (Luo et al. 2011). Furthermore, the rainy season occurs from June to October, just during the harvest season. Residents have to roast freshly harvested corn and chili by burning coal over open oven to dehydrate quickly and hang roasted chilies over the improved oven for defluorination (IOD) to keep dry chilies readily available whenever needed in high-elevation mountainous areas (called roasted corn and roasted chili). They just dry corn and chili by excess heat from cooking or by air naturally, but not with special open oven in the valley area (called non-roasted corn and non-roasted chili).

Two areas were selected as the study areas. Mangbu Town, in Zhenxiong County, is a mountainous region with an altitude of $1,600-1,900 \mathrm{~m}$, and its prevalence rate of DF is $68.5 \%$, and residents live on roasted corn and roasted chili primarily, and on rice and roasted chili occasionally. Mugan Town, in Daguan County, is in a valley region with an altitude of $900-1,200 \mathrm{~m}$, and its prevalence rate of DF is $10 \%$, and residents live on non-roasted corn and non-roasted chili primarily, and on rice and non-roasted chili occasionally (Luo et al. 2011). 
Sample collecting and analysis

Foodstuffs and drinking water samples were collected from Mangbu Town and Mugan Town. The sampling sites included three villages-Yujiawan Village and Wantou Village in the township of Mangbu (typical severe fluorosis village, nearly all residents get severe DF), and Haizi Village in the township of Mugan (typical non-fluorosis village, the prevalence rate of DF is very low) (Fig. 1).

Three drinking water samples from these villages were collected from the groundwater sources. All groundwater samples came from fissure water. The fissure water is one of the main drinking water sources for villages and small towns (Luo et al. 2012). Before sampling, the sampling containers were decontaminated with nitric acid for $24 \mathrm{~h}$, rinsed with tap water first, and finally washed by distilled water. We flushed the containers with sampling water three times at the sampling spots. Water samples were stored in pre-cleaned plastic bottles at $4{ }^{\circ} \mathrm{C}$ before being analyzed. According to $\mathrm{HJ} / \mathrm{T}$ 164-2004, the F and As concentrations in groundwater samples need to be measured within 14 days.

The staple food including rice ( $n=13, n$ is the number of samples), corn flour $(n=25)$, and noodle $(n=13)$ was collected from local residents' home. In this study, we also collected local common vegetables including Chinese cabbage $(n=13)$, potato $(n=13)$, pickle $(n=$ $13)$, and chili $(n=25)$. Corn flour was made after corn peel. Chili powder was directly crushed from chili hanging over IOD. According to eating habits of local residents, rice and vegetables were cleaned with distilled water before dried, but corn flour, noodle, and chili powder were dried without cleaning. All samples were

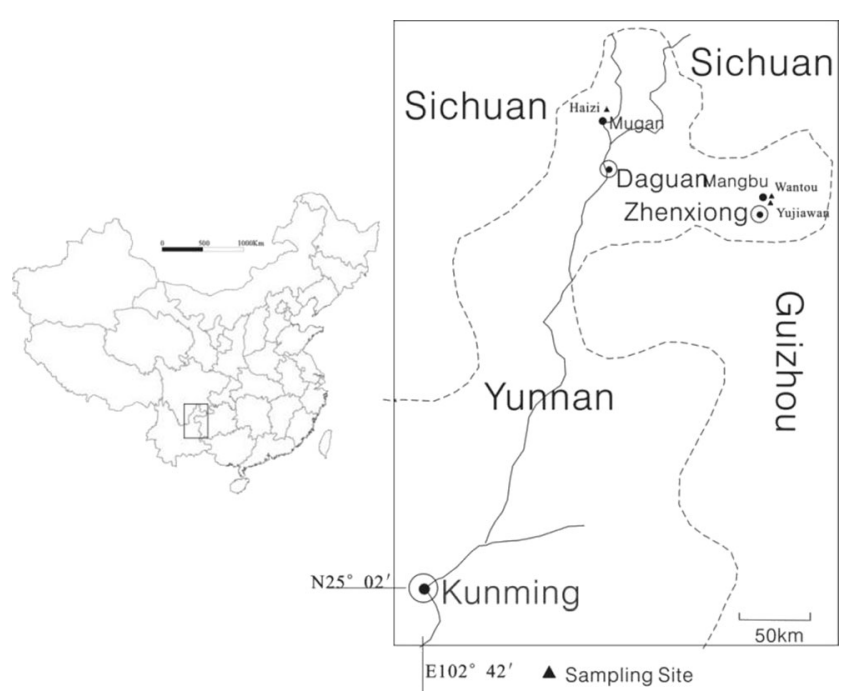

Fig. 1 Location map of the study areas dried at $60{ }^{\circ} \mathrm{C}$ in baking oven and then sieved to 100 meshes for analysis.

Fluoride ion selective electrode and atomic fluorescence spectrometry methods were used to measure the F and As in drinking water, respectively. Fluorine in foodstuffs was determined by the combustion hydrolysis/fluoride ion selective electrode method: $1.0 \mathrm{~g}$ sample was put in a small ceramic boat covered with suitable quartz sand. The boat was gradually put into electric furnace at $1,000{ }^{\circ} \mathrm{C}$, and meanwhile, the condensate was absorbed by $0.2 \mathrm{~mol} / \mathrm{L}$ sodium hydroxide solution. Then, $5 \mathrm{~mL}$ total ionic strength adjusting buffer (TISAB) was added to tested solutions before determination by a fluoride selection electrode and a calomel reference electrode (Shanghai Precision and Scientific Instrument Co. Ltd., China). TISAB was prepared as follows: $145 \mathrm{~g}$ sodium chloride and $7.35 \mathrm{~g}$ sodium citrate were dissolved in $143 \mathrm{~mL}$ acetic acid, and the $\mathrm{pH}$ of solution was adjusted to 5.0-5.5 using $40 \%$ sodium hydroxide solution (GB/ T4633-1997, Feng et al. 2004; Li et al. 2012). Arsenic in samples was measured by hydride generation/atomic fluorescence spectrometry method: Samples were digested with the mixed acid of nitric acid and perchloric acid using electric hot plate (GB/T 5009.11-2003), added with $1 \mathrm{~mL} \mathrm{HCl} \mathrm{(36.5 \% )}$ and $1 \mathrm{~mL}$ reducing agent $(2.5 \%$ sulfourea and $2.5 \%$ ascorbic acid) fixed to $20 \mathrm{~mL}$ by ultrapure water, and measured by AFS-820 (Titan Instruments Company, Beijing, China) finally.

For quality control, standard reference materials (GBW10010 [rice, China], GBW10012 [corn, China], and GBW07602 [bush leaves, China] for corns) and blanks were randomly analyzed with each batch of samples. The correlation coefficients of both $\mathrm{F}$ and As standard curves reach 0.999 . In all our $\mathrm{F}$ and As analyses, the relative standard deviation was less than $10 \%$.

Investigation method

The foodstuffs and drinking water consumptions of a total of 54 residents at different ages were investigated. We investigated 31 residents including 17 residents with a dietary of roasted corn and roasted chili and 14 residents with a dietary of rice and roasted chili in Mangbu Town, and 23 residents including 13 residents with a dietary of non-roasted corn and non-roasted chili and 10 residents with a dietary of rice and nonroasted chili in Mugan Town. The diets including all foodstuffs and drinking water were surveyed in 3 days by asking the housewives, weighed by our investigators (WS/T87-1996).

In addition, to find out the development process of local residents' dietary types, we surveyed 38 households for their present and future possible dietary types in Mangbu Town (as illustrated in Tables 4 and 5). 


\section{Calculation of DFI and DAsI}

The main source of $\mathrm{F}$ and As of human intake is drinking water, indoor air, and foodstuffs (Cao et al. 1996; WS/T87-1996; Jian and Chen 2006; Ponikvar et al. 2007; Xiang et al. 2009):

DFI/DAsI $=\sum C_{\mathrm{i}} I_{\mathrm{i}}$

where DFI is the daily fluorine intake, DAsI is the daily arsenic intake, $C_{\mathrm{i}}$ is the $\mathrm{F} /$ As concentration in environmental medium (foodstuffs, drinking water, and indoor air), and $I_{\mathrm{i}}$ is the amount of daily intake of foodstuffs, drinking water, and indoor air.

Statistical analyses

The data were analyzed by using Microsoft Excel 2007 and SPSS 13.0.

\section{Results}

$\mathrm{F}$ and As concentrations

\section{$F$ and As concentrations in foodstuffs}

From Table 1, F concentration in roasted corn in Mangbu Town $(18.49 \pm 8.23 \mathrm{mg} / \mathrm{kg})$ is much higher than that in nonroasted corn in Mugan Town $(3.17 \pm 0.37 \mathrm{mg} / \mathrm{kg})(p<0.01)$. F in roasted corn is much higher than the permitted levels of $\mathrm{F}$ (PLFs) in grain (1.5 mg/kg) (GB/T 2762-2005) and fresh corn (below $1.5 \mathrm{mg} / \mathrm{kg}$ ) (Li et al. 2012), and $\mathrm{F}$ in non-roasted corn was slightly higher than the PLFs in roasted corn and fresh corn. It showed that a large amount of $\mathrm{F}$ in roasted corn was caused by coal burning, but $\mathrm{F}$ in non-roasted corn increased less, which was consistent with several previous studies (Dai et al. 2004, 2007; Luo et al. 2007, 2010, 2011). F in rice $(0.97 \pm 0.56$ and $1.09 \pm 0.24 \mathrm{mg} / \mathrm{kg}$, respectively) and noodle $(2.02 \pm 0.90$ and $1.93 \pm 0.87 \mathrm{mg} / \mathrm{kg}$, respectively) in both areas was much less than that of the roasted corn $(p<0.01) . \mathrm{F}$ in rice and noodle in Mangbu and Mugan Town was similar to the PLFs in rice and other grains (1.0 and $1.5 \mathrm{mg} / \mathrm{kg}$, respectively) (GB/T 2762-2005). Fluorine in roasted chili powder in Mangbu Town $(92.35 \pm 17.55 \mathrm{mg} / \mathrm{kg})$ was much higher than that in both the other vegetables in this study and the PLFs in vegetables $(2.0 \mathrm{mg} / \mathrm{kg})(\mathrm{GB} / \mathrm{T}$ 2762-2005). Fluorine in roasted chili powder in Mangbu Town was 5-30 times that in non-roasted chili in Mugan Town $((3.51 \pm 051 \mathrm{mg} / \mathrm{kg}) . \mathrm{F}$ in Chinese cabbage, potato, and pickle was similar to the PLFs in vegetables.
As shown in Table 1, As concentration in roasted corn in Mangbu Town $(0.162 \pm 0.121 \mathrm{mg} / \mathrm{kg})$ was much higher than the that in non-roasted corn in Mugan Town $(0.051 \pm$ $0.020 \mathrm{mg} / \mathrm{kg})(p<0.01)$. It is consistent with the previous research results that roasted corn and chili are seriously contaminated with As by dozens of times (Luo et al. 2008, 2010; $\mathrm{Li}$ et al. 2012). Arsenic concentrations in most staple food including non-roasted corn $(0.051 \pm 0.020 \mathrm{mg} / \mathrm{kg})$, rice $(0.110 \pm 0.032$ and $0.075 \pm 0.032 \mathrm{mg} / \mathrm{kg})$, and noodle $(0.024 \pm 0.005$ and $0.031 \pm 0.008 \mathrm{mg} / \mathrm{kg})$ in both areas were much lower than the permitted levels of As (PLAs) in rice and other grain $(0.15$ and $0.2 \mathrm{mg} / \mathrm{kg}$, respectively) (GB/T 2762-2005). Arsenic in roasted chili $(0.782 \pm 0.211 \mathrm{mg} / \mathrm{kg})$ and non-roasted chili $(0.230 \pm 0.082 \mathrm{mg} / \mathrm{kg})$ was much higher than the PLAs in vegetables $(0.05 \mathrm{mg} / \mathrm{kg})$. Arsenic in pickle was much less than the PLAs in vegetables. Arsenic in Chinese cabbage and potato was slightly more than the PLAs in vegetables.

In conclusion, except that $\mathrm{F}$ and As in roasted corn and roasted chili in Mangbu Town were much higher than those in non-roasted corn and non-roasted chili in Mugan Town, F and As in other foodstuffs in these two places were similar. It is worth noting that the corn flour was made after corn peel. F and As concentrations in peeled corn are reduced at different levels, especially As can be reduced by $70 \%$, compared with those in unpeeled corn ( $\mathrm{Li}$ and Luo 2010). The residents eat a little chili powder for seasoning purpose, not as a true vegetable.

\section{$F$ and As concentrations in drinking water}

There were two drinking water sources in Mangbu Town and one source in Mugan Town. As showed in Table 1, F and As concentrations in drinking water from these water sources were $0.21 \mathrm{mg} / \mathrm{L}$ (mean) and $0.22 \mathrm{mg} / \mathrm{L}$, and $0.187 \mu \mathrm{g} / \mathrm{L}$ (mean) and $0.310 \mu \mathrm{g} / \mathrm{L}$, respectively. The results were consistent with previous studies (Luo et al. 2007, 2008, 2012; Dai et al. 2004). All were much lower than the PLFs and PLAs in drinking water $(1.0$ and $0.01 \mathrm{mg} / \mathrm{L}$, respectively) (GB $5749-2006)$ and the recommendations $(1.5 \mathrm{mg} / \mathrm{kg}$ and $0.01 \mathrm{mg} / \mathrm{L}$, respectively) by WHO (1996), and also much lower than the fluorosis area Shannxi $(1.17 \mathrm{mg} / \mathrm{L}$ and $10 \mu \mathrm{g} / \mathrm{L}$, respectively (Zhu et al. 2006)).

\section{$F$ and As concentrations for indoor air in bedroom and living} room

Almost all households were IOD users and the air quality has met Chinese standards in Zhaotong City (Liu et al. 1999; Li and Long 2005). F and As concentrations for indoor air in the baking room were much higher than those in the bedroom and living room (Jin et al. 2003; Liu et al. 2013). According to our field investigation, the baking room and living room are 
Table $1 \mathrm{~F}$ and As concentrations in foodstuffs from households and drinking water from water source in investigated areas (dry basis, $\mathrm{mg} / \mathrm{kg}$ )

\begin{tabular}{|c|c|c|c|c|c|c|c|c|c|c|c|c|c|c|c|c|c|}
\hline \multirow[t]{2}{*}{ Area } & & \multicolumn{2}{|l|}{ Rice } & \multicolumn{2}{|l|}{ Corn } & \multicolumn{2}{|c|}{ Noodle } & \multicolumn{2}{|l|}{ Chili } & \multicolumn{2}{|c|}{ Chinese cabbage } & \multicolumn{2}{|c|}{ Potato } & \multicolumn{2}{|c|}{ Pickle } & \multicolumn{2}{|c|}{ Drinking water } \\
\hline & & $\mathrm{F}$ & As & $\mathrm{F}$ & As & $\mathrm{F}$ & As & $\mathrm{F}$ & As & $\mathrm{F}$ & As & $\mathrm{F}$ & As & $\mathrm{F}$ & As & $\mathrm{F}(\mathrm{mg} / \mathrm{L})$ & As $(\mu \mathrm{g} / \mathrm{L})$ \\
\hline & $n$ & 8 & & $15^{\mathrm{a}}$ & & 8 & & $15^{\mathrm{a}}$ & & 8 & & 8 & & 8 & & 2 & \\
\hline \multirow[t]{6}{*}{ Mangbu Town } & $\min$ & 0.39 & 0.032 & 7.10 & 0.021 & 0.81 & 0.005 & 101.02 & 0.548 & 1.07 & 0.023 & 0.98 & 0.007 & 0.23 & 0.035 & 0.15 & 0.127 \\
\hline & $\max$ & 1.63 & 0.153 & 28.62 & 0.262 & 2.89 & 0.028 & 219.44 & 1.024 & 4.31 & 0.122 & 3.57 & 0.025 & 0.89 & 0.164 & 0.26 & 0.247 \\
\hline & & 0.97 & 0.110 & 18.49 & 0.162 & 2.02 & 0.024 & 154.25 & 0.782 & 3.09 & 0.072 & 2.21 & 0.016 & 0.55 & 0.114 & 0.205 & 0.187 \\
\hline & $\mathrm{s}$ & 0.56 & 0.032 & 8.23 & 0.121 & 0.81 & 0.005 & 57.55 & 0.211 & 1.07 & 0.045 & 1.19 & 0.008 & 0.27 & 0.058 & & \\
\hline & $n$ & 5 & & $10^{\mathrm{b}}$ & & 5 & & $10^{\mathrm{b}}$ & & 5 & & 5 & & 5 & & 1 & \\
\hline & $\min$ & 0.24 & 0.032 & 2.37 & 0.022 & 0.87 & 0.008 & 2.98 & 0.134 & 0.63 & 0.038 & 0.74 & 0.000 & 0.34 & 0.010 & 0.22 & 0.310 \\
\hline \multirow[t]{3}{*}{ Mugan Town } & $\max$ & 1.30 & 0.100 & 3.91 & 0.089 & 2.68 & 0.037 & 3.99 & 0.308 & 3.21 & 0.217 & 3.51 & 0.012 & 1.44 & 0.108 & & \\
\hline & & 1.09 & 0.075 & 3.17 & 0.051 & 1.93 & 0.031 & 3.51 & 0.230 & 2.27 & 0.128 & 2.18 & 0.006 & 1.04 & 0.067 & & \\
\hline & $\mathrm{s}$ & 0.24 & 0.032 & 0.67 & 0.020 & 0.87 & 0.008 & 0.51 & 0.082 & 1.34 & 0.076 & 1.23 & 0.005 & 0.54 & 0.049 & & \\
\hline
\end{tabular}

${ }^{\mathrm{a}}$ Roasted

${ }^{\mathrm{b}}$ Non-roasted

separate and independent from one another. Moreover, the baking room is generally enclosed during baking time of 10-15 days, and $\mathrm{F}$ and As concentrations in baking room have a little influence on human health. Therefore, according to references and our field investigation, we did not measure the $\mathrm{F}$ and As concentrations for indoor air quality. From the data of Zhenxiong County Environment Survey Station, the average F concentration for indoor air in bedroom and living room was $0.007 \mathrm{mg} / \mathrm{m}^{3}$, and As concentration for indoor air was considered as $1.6 \mu \mathrm{g} / \mathrm{m}^{3}$ according to Jin et al. (2003).

Food consumption of residents

Due to lack of reliable transportation and poor economy in the studied area, most people cannot afford commodity grain such as rice or wheat flour. The diet structure of countrymen is very simple. Most of them have to feed with their own grains and vegetables. They seldom eat meat except on important occasions. In addition, all local residents including weaning infants love chili as their daily necessary seasoning. Both adults and children like to drink unboiled water. They are not in a habit of drinking tea or beverage. They seldom brush teeth.

Based on our investigation, Table 2 shows daily foodstuff and drinking water consumption in two investigated areas. We could see that the diet structure of both areas is similar except for staple food and chili type. It is because the two areas are in the same geographical region. According to WS/T87-1996, an adult aged over 15 years needs $12 \mathrm{~m}^{3}$ of air per day, and a child aged 8-15 years needs $9 \mathrm{~m}^{3}$ of air per day. According to oxygen demand of different ages, we assume that a child aged 3-7 years needs $6 \mathrm{~m}^{3}$ of air per day.

\section{DFI and DAsI of residents}

Based on $\mathrm{F}$ and As concentrations in the selected foodstuff materials and daily food consumption of residents in the $\mathrm{F}$ and As concentrations and Food consumption of residents sections, we calculated DFI and DAsI of residents with these dietary types using Eq. (1).

\section{DFI of residents}

From Table 3, the DFI for residents with the dietary type of roasted corn and roasted chili for age groups $3-7,8-15$, and over 15 years was $5.06,9.60$, and $14.38 \mathrm{mg}$, respectively, all of which were much higher than that for the residents in the same age group with other dietary types. The DFI for residents of the same age groups with the dietary type of rice and roasted chili $(1.94,3.50$, and $4.95 \mathrm{mg}$, respectively) was higher than that of the non-roasted corn and non-roasted chili type $(1.19,2.05$, and $2.97 \mathrm{mg}$, respectively) and the rice and non-roasted chili type $(0.85,1.40$, and $1.91 \mathrm{mg}$, respectively).

From Fig. 2 (DFI), for residents with the dietary type of roasted corn and roasted chili, DFI from roasted corn accounted for $70 \%$ of total DFI, and from chili, it accounted for $23 \%$. For residents with the dietary type of rice and roasted chili, DFI from chili accounted for $65 \%$ of total DFI. Therefore, roasted corn and roasted chili are the main sources of DFI for these residents. However, for residents with the dietary types of both non-roasted corn/non-roasted chili and rice/non-roasted chili, DFI from chili can be ignored. The main sources of DFI for the two types are staple food and drinking water. 


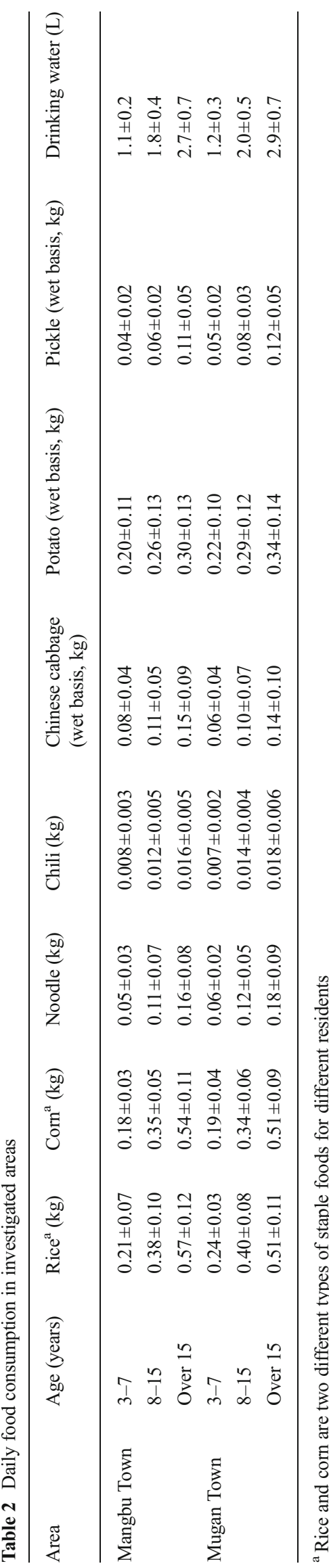

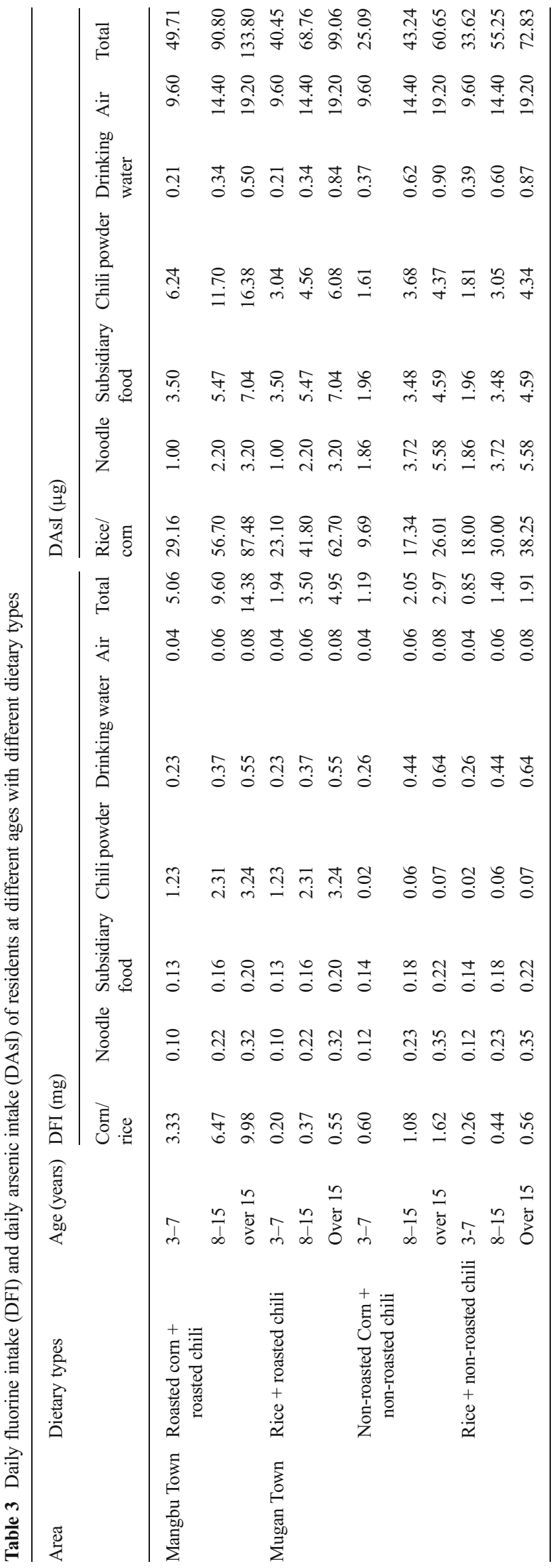




\section{DAsI of residents}

From Table 3, the average DAsI for residents with the dietary type of roasted corn and roasted chili in age groups 3-7, 8-15, and over 15 years was $49.71,90.80$, and $133.80 \mu \mathrm{g}$, respectively, which were slightly higher than that for residents in the same age group with rice and roasted chili (40.45, 68.76, and $99.06 \mu \mathrm{g}$, respectively), non-roasted corn and non-roasted chili $(25.09,43.24$, and $60.65 \mu \mathrm{g}$, respectively), and rice and non-roasted chili $(33.62,55.25$, and $72.83 \mu \mathrm{g}$, respectively). The DAsI for residents with dietary types of rice/non-roasted chili and non-roasted corn/non-roasted chili was similar.

As shown in Fig. 2 (DAsI), DAsI from staple food accounts for over $45 \%$ of total DAsI, and from air, it accounts for more than $15 \%$ for all residents consuming any kind of diet; DAsI from drinking water has very little influence and can be ignored.

\section{Development process of the dietary types}

From Table 4, the households whose staple food were rice or mainly rice accounted for $52.6 \%$ of all investigated households, and the other $47.4 \%$ lived on corn or mainly corn. Specifically, the staple food of all the householders below 35 years old was rice or mainly rice, while the staple food of about $65 \%$ of the other householders over 35 years old was corn or mainly corn. From Table 5, the reason for $66.7 \%$ of householders choosing corn as staple food was for economic reason since rice is more expensive than their own grown corn, and the reason for $33.3 \%$ of householders choosing corn was because corn is more delicious. The reason for $90.0 \%$ of householders choosing rice as staple food was because rice is more delicious and easier to cook. Over $60 \%$ of householders would like to eat rice or mainly rice as staple food, while only $18.4 \%$ of householders with $100 \%$ householders aged over 35 would like to eat corn or mainly corn as staple food. This means that rice is their preferred staple food for local residents. Almost all residents would not change their habit of eating chili as seasoning.

\section{Discussion}

As dental calcification of children is completed before an age of 6-8 years old, DFI for children during this period will decide whether their teeth will take pathologic change. The DFI for the children aged 3-7 years with a dietary of roasted corn and roasted chili was $5.06 \mathrm{mg}$, which was much higher than the RDAs of USA (1.5-2.5 mg) (BCLSNR 1980). The DFI of the children aged 3-7 years with dietaries of rice/ roasted chili (1.94 mg) and non-roasted corn/non-roasted chili (1.19 mg) was within the RDAs of USA. The DFI of the children aged 3-7 years with a dietary of rice/non-roasted chili $(0.85 \mathrm{mg})$ was less than the RDAs in USA. According to DF epidemiological investigation for residents, we concluded that the DF prevalence rates for children aged 9-14 years with different dietary types before the age of 6 years were $100 \%$ with $95 \%$ having very mild DF for children living on roasted corn and roasted chili, $5.6 \%$ with $100 \%$ having very mild DF for children living on rice and roasted chili, $16.7 \%$ with $100 \%$ having very mild DF for children living on nonroasted corn and non-roasted chili, and no one got DF living on rice and non-roasted chili (Luo et al. 2011). The results verified the adaptation of RDAs of USA in coal-burning fluorosis regions in Southwest China. The AI for fluorine from all sources is set at $0.05 \mathrm{mg} / \mathrm{day} / \mathrm{kg}$ bodyweight (FNB 1997). It is assumed the weight of a child aged 3-7 years is $10-20 \mathrm{~kg}$ and the AI for $\mathrm{F}$ is calculated as $0.5-1 \mathrm{mg}$. Therefore, the children have little risk for getting DC in this

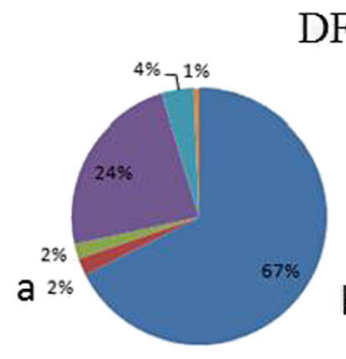

DFI
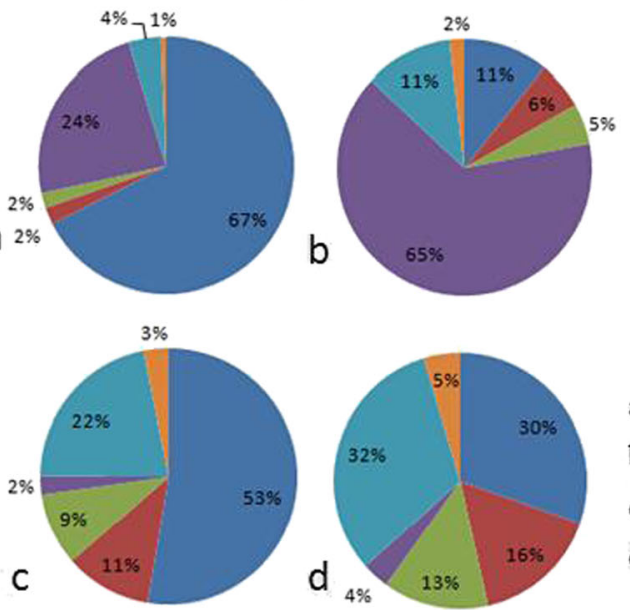

ecomírice

= noodle

= Subsidiary food

a Chili powder

= Drinking water

$=$ Air

a: roasted corn+roasted chili

b: rice+roasted chili

c:non-roasted corn + non-roasted chili

d:rice+non-roasted chili

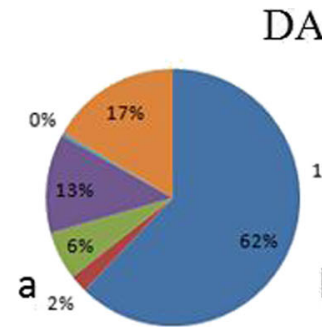

DAsI
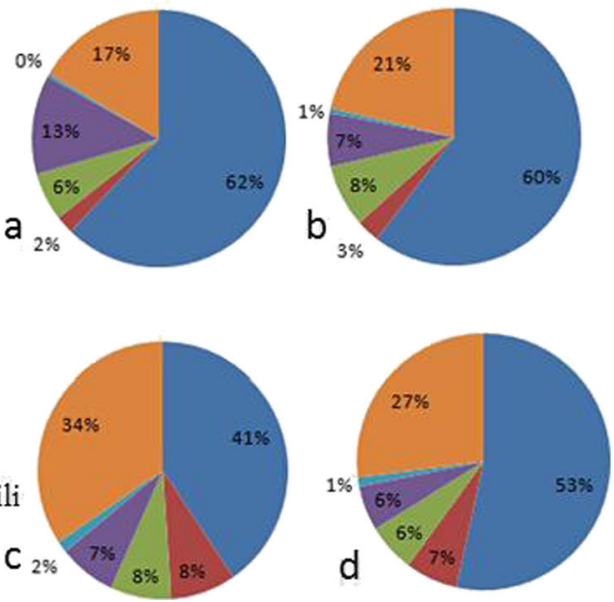

Fig. 2 Percentages of various sources in total DFI and DAsI 
Table 4 The present and future possible dietary style of respondents

\begin{tabular}{|c|c|c|c|c|c|c|c|c|c|}
\hline \multirow[t]{2}{*}{ Variable } & \multirow[t]{2}{*}{ Age group (years) } & \multicolumn{2}{|c|}{$20-35(11)$} & \multicolumn{2}{|c|}{$35-45(13)$} & \multicolumn{2}{|c|}{$>45(14)$} & \multicolumn{2}{|l|}{ Total } \\
\hline & & Count & Percent & Count & Percent & Count & Percent & Count & Percent \\
\hline \multirow[t]{5}{*}{ Present staple food } & Rice & 8 & 72.7 & 2 & 15.4 & 1 & 7.1 & 11 & 28.9 \\
\hline & Rice based, corn occasionally & 3 & 33.3 & 2 & 15.4 & 4 & 28.6 & 9 & 23.7 \\
\hline & Corn based, rice occasionally & 0 & 0 & 8 & 61.5 & 8 & 57.2 & 16 & 42.1 \\
\hline & Corn & 0 & 0 & 1 & 7.7 & 1 & 7.1 & 2 & 5.3 \\
\hline & Total & 11 & 100 & 13 & 100 & 14 & 100 & 38 & 100 \\
\hline \multirow[t]{4}{*}{ Future staple food } & Rice & 9 & 81.8 & 3 & 23.2 & 2 & 14.3 & 14 & 36.8 \\
\hline & Rice based, corn occasionally & 2 & 18.2 & 5 & 38.4 & 10 & 71.4 & 17 & 36.8 \\
\hline & Corn based, rice occasionally & 0 & 0 & 5 & 38.4 & 2 & 14.3 & 7 & 18.4 \\
\hline & Total & 11 & 100 & 13 & 100 & 14 & 100 & 38 & 100 \\
\hline \multirow[t]{2}{*}{ Chili powder } & Change & 1 & 100 & 0 & 0 & 0 & 0 & 1 & 2.6 \\
\hline & Not change & 10 & 27.0 & 13 & 35.1 & 14 & 37.8 & 37 & 97.4 \\
\hline
\end{tabular}

study area. It is consistent with Lu et al.'s (2009) investigation that the prevalence rate for dental caries for children in Zhaotong was the lowest in 16 regions of Yunnan Province. Furthermore, if residents have continuously exposed Fcontaminated environment through ingestion and inhalation, they will get SF at their 40s. There have been several reports that SF was very popular in middle ages and elders (Jian and Chen 2006; Luo et al. 2008). The DFI for the children (715 years) and adults (over 15 years) with a dietary of roasted corn and roasted chili was 9.60 and $14.38 \mathrm{mg}$, respectively, which were much higher than RDAs of USA $(1.5-4.0 \mathrm{mg}$ ) (BCLSNR 1989) and of China (2.0 and $3.0 \mathrm{mg}$, respectively) (WS/T 96-2005). The DFI for the children and adults with a dietary of rice and roasted chili was 3.50 and $4.95 \mathrm{mg}$, respectively, both of which were slightly higher than the RDAs of USA and China. The DFI for the children and adults with dietaries of both non-roasted corn/non-roasted chili (2.05 and $2.97 \mathrm{mg}$, respectively) and rice/non-roasted chili (1.40 and $1.91 \mathrm{mg}$, respectively) was less than the RDAs of USA and China. According to Jian and Chen (2006), residents did not get SF when DFI was $1.81 \mathrm{mg}$, while the prevalence rate of SF of the elders over 55 years old reached $28.6 \%$ when DFI was $4.48 \mathrm{mg}$. From this, the residents with a dietary of roasted corn

Table 5 Main reason for choosing present staple food

\begin{tabular}{llrl}
\hline Choice & Reasons (multiple choice) & Count & Percent \\
\hline Corn or mainly corn & More delicious & 6 & 33.3 \\
& Economic reasons & 12 & 66.7 \\
& Eating corn makes people & 3 & 16.7 \\
& $\quad$ feel strong to work & & \\
Rice or mainly rice & More delicious & 18 & 90.0 \\
& Easier to cook & 8 & 40.0 \\
\hline
\end{tabular}

and roasted chili have a high risk for getting SF and the residents living on rice and roasted chili also have a certain risk for getting SF. However, we still lack information on the SF prevalence rate for residents with different dietary types, and further study is needed to find the corresponding relation between the DFI and SF prevalence rate with different dietary types in Southwest China.

DAsI for residents with different dietary types at different ages ranged from 25 to $135 \mu \mathrm{g}$, all of which were lower than the recommendation $(128 \mu \mathrm{g})$ by FAO/WHO (1988) and ( $\mathrm{Li}$ et al.'s (2006) research value $(276.1 \mu \mathrm{g})$. Therefore, As polluted in foodstuffs alone will not influence human health. There was not much difference in DAsI between roasted corn and rice as staple food. However, compared with the DAsI of residents living on fresh corn, the DAsI for roasted corn increases greatly ( $\mathrm{Li}$ et al. 2012). As and F may have synergy effect on fluorosis and As poisoning (An et al. 1992; Li et al. 1996). Therefore, the As-polluted roasted corn and chili by coal burning may have an important influence on fluorosis and As poisoning.

Local residents are changing their staple food from corn flour to rice, and especially, younger people who value quality life prefer to spend more on rice because it is more delicious and much easier to cook. However, even if local residents have changed their staple food, they will not change their habit of chili powder as seasoning for a long time. So we should pay more attention to $\mathrm{F}$ intake from chili which may have influence on human health. People have the habit of stringing chilies together and hanging them on the IOD to roast and keep them dry so they can take them whenever needed during wet seasons. $\mathrm{F}$ in coal is easily absorbed by chilies in the process of adding coal during cooking. $\mathrm{F}$ concentration in chilies can even reach $455 \mathrm{mg} / \mathrm{kg}$ (Luo et al. 2010). In our studies, if a person eats $20 \mathrm{~g}$ of chili per day, he/she 
will take $\mathrm{F}$ of $9.9 \mathrm{~g}$ per day, which is much higher than the RDAs of USA and China.

From the economic situation of Zhaotong City, how much is the risk of fluorosis? The annual income of rural residents has been increasing yearly in Zhaotong. The average annual income for farmers in 2012(\$638) was three times that in 2003 (Statistical Bureau of Zhaotong City 2003-2012). However, Zhaotong ranks last in 14 cities of Yunnan Province. According to our field investigation, the economy situation and dietary habits of residents in Mangbu Town are better than other remote towns. People in developed regions can hardly imagine what a rough life the local countrymen living in mountainous areas have. They have to live on roasted corn and chili as their staple food and mainly vegetable once they are weaned. Therefore, we must see the difficulty to change the dietary habits of residents and to reduce the fluorosis risk in rural areas.

In conclusion, some measures can be taken to reduce fluorosis risk: (1) vigorously develop the local economy and encourage and guide the residents to eat rice as staple food, not roasted corn flour. All levels of governments have to offer certain subsidies to residents in the future. And, (2) it is very hard to give up chili powder as seasoning for local residents. Local centers for disease control and prevention should guide the residents to keep chili in sealed bags after drying and to avoid hanging it over IOD all the time.

\section{Conclusions}

The DFI for residents with a dietary of roasted corn and roasted chili was $5.06,9.60$, and $14.38 \mathrm{mg}$ for age groups $3-$ $7,8-15$, and over 15 years, respectively. Over $90 \%$ of DFI was from roasted foodstuffs. The DFI for residents of the same age group living on rice and roasted chili was $1.94,3.50$, and $4.95 \mathrm{mg}$, respectively, which are less than that in the former dietary type, and $65 \%$ of DFI was from roasted chili. The main sources for their DFI are roasted foodstuffs. Both were higher than the dietaries with non-roasted foodstuffs and the recommended daily allowances (RDAs) for USA and China at different levels. The DAsI for all residents ranged from 25 to $135 \mu \mathrm{g}$, and at this level of DAsI, it would not influence human health. However, As pollution of roasted foodstuffs might have an important influence for the fluorosis. Residents are changing their staple food from roasted corn to rice, and especially, younger people are more focused on quality life. However, even if residents change their staple food, the habit of eating chili will not change, which may also cause them getting fluorosis. Developing economy, changing dietary types, and changing the habit of drying and keeping chili will help to reduce the fluorosis risk in coal-burning fluorosis area of Southwest China.

Acknowledgments This research was supported by the National Key Basic Research Program of China (973 Program) (No. 2014CB238906), the National Natural Science Foundation of China (Grant No. 40872210, 41172310), and the National High Technology Research and Development Program (863) of China (Grant Nos. 2004AA601080 and 2006AA06Z380). Many heartfelt thanks are given to the whole staff of Zhaotong City Science and Technology Bureau and local residents for their strong supports and active cooperation. We thank Dr. Hui-jie Li for assistance during the investigation and Yong-xin $\mathrm{Xu}$ and Run-xiang Ni in determining the $\mathrm{F}$ and As concentrations in samples. We also thank James Law for his selfless help in improving the language. We appreciate the editor and reviewers' constructive suggestions for the whole paper.

\section{References}

Abida F, Harue M, Nousheen F (2007) Toxic fluoride and arsenic contaminated groundwater in the Lahore and Kasur districts, Punjab, Pakistan and possible contaminant sources. Environ Pollut 145: 839-849

An D, He GY, Hu XQ (1992) Arsenic-fluoride poisoning of coal-burning pollution. Guizhou Med 16:1-5 (in Chinese)

Ando M, Tadano M, Yamamoto S, Tamura K, Asanuma S, Watanabe T, Kondo T, Sakurai S, Ji R, Liang C, Chen X, Hong Z, Cao S (2001) Health effects of fluoride pollution caused by coal burning. Sci Total Environ 271:107-116

Bell MC, Ludwig TG (1970) The supply of fluoride to man: ingestion from water. Fluoride and Human Health, WHO Monograph Series. World Health Organization, Geneva

Board Commission on Life Sciences National Research Council (BCLSNR) (1980) Recommended daily allowance (RDAs) 9th. National Academy Press, Washington

Board Commission on Life Sciences National Research Council (BCLSNR) (1989) Recommended daily allowance (RDAs) 10th. National Academy Press, Washington

Cao J, Zhao Y, Liu JW, Liu JW, Bai XX, Zhou DY, Fang SL, Jia M, Wu JS (1996) Fluorine intake of a Tibetan population. Food Chem Toxicol 34:755-757

Cao J, Zhao Y, Liu JW et al (2003) Prevention and control of brick-tea type fluorosis - a 3-year observation in Dangxiong, Tibet. Ecotoxicol Environ Saf 56:222-227

Dai SF, Ren DY, Ma SM (2004) The cause of endemic fluorosis in western Guizhou Province, Southwest China. Fuel 83:2095-2098

Dai SF, Li WW, Tang YG, Feng YP (2007) The sources, pathway, and preventive measures for fluorosis in Zhijin County, Guizhou, China. Appl Geochem 22:1017-1024

Dai SF, Ren DY, Chou CL, Finkelman RB, Seredin VV, Zhou Y (2012) Geochemistry of trace elements in Chinese coals: a review of abundances, genetic types, impacts on human health, and industrial utilization. Int J Coal Geol 94:3-21

Feng FJ, Liu XP, Yu JP, Wang WY, Luo KL (2004) Determination of fluoride in the environmental samples by combustion-hydrolysision selective electrode method. J Hyg Res 33:289-291 (in Chinese)

Finkelman RB, Belkin HE, Zheng BS (1999) Health impacts of domestic coal use in China. Proc Natl Acad Sci U S A 96:3427-3431

Food and Agriculture Organization/ World Health Organization (FAO/ WHO) (1988) Codex Alimentarius, General Standard for Contaminants and Toxins in Food. Geneva

Food and Nutrition Board (FNB) (1997) Dietary reference intakes (DRI) for calcium, phosphorus, magnesium, vitamin $\mathrm{D}$, and fluoride. 
National research council (302-303). National Academy Press, Washington

Harrison PTC (2005) Fluoride in water: a UK perspective. J Fluor Chem 126:1448-1456

Jian ZS, Chen SQ (2006) The relationship between prevalence rate of fluorosis and fluorine intake. J Public Health Prev Med 17: 82-83 (in Chinese)

Jin YL, Liang CK, He GL (2003) Study on distribution of endemic arsenic poisoning in China. J Hyg Res 32:519-540 (in Chinese)

Kaseva M (2006) Contribution of trona(magadi) into excessive fluorosis - a case study in Majiya Chaiward, northern Tanzania. Sci Total Environ 366:92-100

Li LC, Long ZG (2005) Epidemiology investigation of endemic fluorosis and discussion about the effect of improved oven for defluorination. Mod Med Health 21:2395-2396 (in Chinese)

Li HJ, Luo KL (2010) Effect of open storage and peeling on the fluorine content of dried corn in Zhaotong City, Yunnan Province, a fluorosis area. Chin J Endemiol 29:426-431 (in Chinese)

Li DS, Cutress TW, Li XS (1996) An experimental study on effects of arsenic on dental fluorosis in rats. Chin J Prev Med 30:354-356 (in Chinese)

Li XW, Gao JQ, Wang YF (2006) Chinese total dietary study-the dietary arsenic intakes in 2000. J Hyg Res 35:63-66 (in Chinese)

Li L, Luo KL, Liu YL, Xu YX (2012) The pollution control of fluorine and arsenic in roasted corn in "coal-burning" fluorosis. J Hazard Mater 229-230:57-65

Liteplo R, Howe P, Malcolm HM (2002) Environmental health criteria number: 227 Fluorides. World Health Organization, Geneva

Liu W, Wang RY, Guo XC (1999) The twelve-year effect observation of improved oven for defluorination in coal-burning fluorosis area. Chin J Endemiol 18:312 (in Chinese)

Liu YL, Luo KL, Li L, Shahid MZ (2013) Fluoride and sulfur dioxide indoor pollution situation and control in coal-burning endemic area in Zhaotong, Yunnan. China Atmos Environ 77:725-737

Lu M, Fang SH, Liu JT (2009) The investigation of dental caries of children aged 3-6 in 16 prefectures and 12 nations in Yunnan Province. Matern Child Health Care China 24:100 101 (in Chinese)

Luo KL, Li HJ, Feng FJ, Chen TB, Xiong M (2007) Content and distribution of fluoride in rock, clay and water in fluorosis area Zhaotong, Yunnan Province. J China Coal Soc 32:363368 (in Chinese)

Luo KL, Li HJ, Chen TB, Wang WZ, Bi SG, Wu XZ, Li W, Wang LH (2008) Content of arsenic, selenium, mercury in the coal, food, clay and drinking water in the Zhaotong fluorosis area, eastern Yunnan Province. J China Coal Soc 33:289-294 (in Chinese)

Luo KL, Li HJ, Niu CX (2010) Fluorine and arsenic pollution route of grain in Yunnan-Guizhou coal-burning endemic fluorosis area. Geol Rev 56:289-298 (in Chinese)
Luo KL, Li L, Zhang SX (2011) Coal-burning roasted corn and chili as the cause of dental fluorosis for children in southwestern China. J Hazard Mater 185:1340-1347

Luo KL, Liu YL, Li HJ (2012) Fluorine content and distribution pattern in groundwater of eastern Yunnan and western Guizhou, China. Environ Geochem Health 34:89-101

Mandinic Z, Curcic M, Antonijevic B, Carevic M, Mandic J (2010) Fluoride in drinking water and dental fluorosis. Sci Total Environ 408:3507-3512

Ministry of Health of the People's Republic of China (1996) Hygienic standard for daily total intake fluoride (WS/T87-1996) (in Chinese)

Ministry of Health of the People's Republic of China (2005) Maximum levels of contaminants in foods (GB/T 2762-2005) (in Chinese)

Ministry of Health of the People's Republic of China (2007) Drinking Water Standards (GB 5749-2006) (in Chinese)

National Environmental Protection Bureau of the People's Republic of China (2004) Technical specifications for environmental monitoring of groundwater (HJ/T164-2004) (in Chinese)

Ponikvar M, Vekoslava S, Boris Z (2007) Daily dietary intake of fluoride by Slovenian Military based on analysis of total fluorine in total diet samples using fluoride ion selective electrode. Food Chem 103:369-374

Reference Values for Nutrition Intake (2002) Bonn, German Nutrition Society, Austrian Nutrition Society, Swiss Society for Nutrition Research, Swiss Nutrition Association

Statistical Bureau of Zhaotong City (2003-2012) Statistical bulletin for national economic and social development of Zhaotong City. http://www.ztstats.gov.cn/tjgb/

The State Bureau of Technology of the People's Republic of China (1997). Determination of fluoride in coal (GB/T4633-1997)

World Health Organization (WHO) (1985) Guideline for the study of Dietary Intake of Chemical Contaminants. Switzerland, Geneva

World Health Organization (WHO) (1996) Guidelines for Drinking-water Quality: Recommendations. Switzerland, Geneva

World Health Organization (WHO) (2002) Environmental health criteria 227 fluorides, Geneva, Switzerland

Xiang QY, Zhou MH, Wu M et al (2009) Relationships between daily total fluoride intake and dental fluorosis and dental caries. J Nanjing Med Univ 23:33-39

Ye F, Yang GR, Peng HB, Wang AW, Yang CG (2004a) Analysis of coalcombustion endemic fluorosis survey of Zhaotong in Yunnan Province in 2002. Ende Dis Bul 19:63-64 (in Chinese)

Ye F, Yang GR, Peng HB, Wang AW, Zhou ZZ, Cao ZP, Meng JH, Zhou GL, Zhang YK, Chen ZS, Wang AW (2004b) Analysis of the key investigation result of coal burning endemic fluorosis in Zhenxiong County. Ende Dis Bull 19:41-42 (in Chinese)

Zhu CS, Bai GL, Liu XL, Li Y (2006) Screening high-fluoride and higharsenic drinking waters and surveying endemic fluorosis and arsenism in Shaanxi province in western China. Water Res 40:3015-3022 